Serological and bacteriophage typing of the organisms showed that the same strains were persistently isolated from most subjects, and sometimes two different strains of the same species were repeatedly present.

\title{
Comment
}

Little work has been done on the effect of wearing rings on the microflora of skin. One study showed an increase in the normal Gram positive flora but did not mention colonisation by Gram negative organisms. ${ }^{1}$ The pattern of isolation of Gram negative bacilli in our study suggested that these organisms are colonisers rather than transient contaminants because the same strains were persistently isolated over several months. Repeated isolation of Ent agglomerans, Kleb pneumoniae, and Ps aeruginosa from the whole hand has previously been shown. ${ }^{23}$ Much attention has been given to hands as vectors of infection in hospitals, and direct contact is an effective method of transfer. ${ }^{4}$ The clinical importance of such carriage remains to be evaluated, but as the organisms isolated include those responsible for many infections in hospitals, ${ }^{5}$ the possibility that such bacteria can permanently colonise the hands of hospital staff wearing rings should be borne in mind in high risk wards and theatres.

We thank Mrs J A Crees-Morris, Mr H Todd, and Mr M A Gaston for typing isolates, and $\mathrm{Mr} \mathrm{C} \mathrm{A} \mathrm{Mackintosh} \mathrm{for} \mathrm{statistical} \mathrm{analysis.}$

1 Medical Research Council Subcommittee. Aseptic methods in the operating suite. Lancet 1968; ; :705-9.

2 Adams BG, Marrie TJ. Hand carriage of aerobic Gram negative rods may not be transient. F Hyg (Camb) 1982;89:33-46.

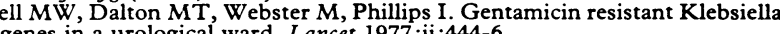
Lancet 1977; ii :444-6.

4 Mackintosh CA, Hoffman PN. An extended model for transfer of micro-organisms via the hands: differences between organisms and the effect of alcohol disinfection. F Hyg (Camb) 1984;92:345-55.

5 Marples RR, Mackintosh CA, Meers PD. Microbiological aspects of the 1980

national prevalence survey of infection in hospitals. $\mathcal{F}$ Hosp Infect 1984;5:172-80.

(Accepted 26 October 1984)

Division of Hospital Infection, Central Public Health Laboratory, London NW9 5HT

P N HOFFMAN, BSC, senior microbiologist

E M COOKE, MD, FRCPATH, director

Whittington Hospital, London N19 5NF

M R MCCARVILLE, SRN, SCM, infection control sister

A M EMMERSON, MB, FRCPATH, consultant microbiologist

\section{Frontal sinusitis caused by Myriodontium keratinophilum}

We report the first case of infection with Myriodontium keratinophilum in man.

\section{Case report}

A 53 year old Nigerian business man was healthy until early 1980, when he suffered from facial pain. Sinusitis secondary to nasal polyps was diagnosed, and nasal polypectomy was performed in Ibadan in March. The polyps recurred often and at short intervals, so polypectomy was repeated in April 1980, May 1982, and August 1982. Four months after this last operation he noticed a swelling on his forehead, which gradually enlarged and was accompanied by left proptosis.

A mucocele of the frontal sinus was diagnosed clinically and radiologically, but when an osteoplastic frontal flap was raised in September 1983 the sinus was found to contain brown necrotic like material. This had eroded the roof of the left orbit and both ethmoid bones, causing polypoidal mucosa to block both sides of the nose. The posterior wall of the frontal sinus was thinned and eroded. The eosinophil count was $4 \%$ and the erythrocyte sedimentation rate $61 \mathrm{~mm}$ in the first hour. The frontal and ethmoidal sinuses were exenterated and drainage tubes placed in the frontal sinus via the nose.

The tissue lining the sinus consisted of floridly inflamed granulation tissue containing large numbers of plasma cells and eosinophils; most of the mucosal lining was ulcerated. Few macrophages were present, there were no giant cells, and there was no evidence that the tissue had been invaded by the fungus in the lumen. The contents of the sinus were mainly cellular debris containing Charcot-Leyden crystals with some foci of viable cells, including eosinophils. Scattered throughout were fungal hyphae, which were scanty in most areas. The hyphae were branched and septate

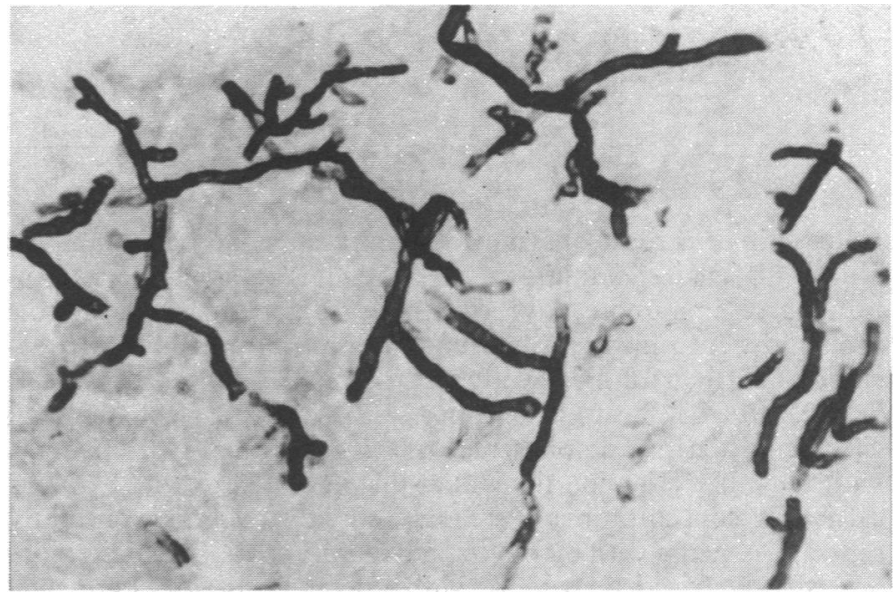

Histological section of contents of frontal sinus, showing hyphae of $M$ keratinophilum. Methenamine silver $\times 750$ (original magnification).

(figure) and were initially thought to be a species of Aspergillus. Closer examination showed that they differed from aspergillus because they branched non-dichotomously and appeared ribbon like and folded. These features are characteristic of mycetoma of the paranasal sinus seen in the Sudan $^{2}$ and of allergic aspergillosis of the paranasal sinus. ${ }^{3}$

Growth of the hyphae yielded a slow growing white mould that produced a few single celled conidia on long denticles along the sides of the fertile hyphae. This isolate was identified by Dr B L Brady, Commonwealth Mycological Institute, Kew, Surrey, as $M$ keratinophilum. An antigenic extract prepared from the isolate produced a single diffuse precipitin line when it was tested against the patient's serum by double diffusion. No reaction was observed when comparable extracts of $A$ flavus, $A$ fumigatus, and $A$ versicolor were tested against the serum.

The patient was treated with ketoconazole $200 \mathrm{mg}$ daily for three weeks, returned to Nigeria, and had recovered by October 1984 with no recurrence.

\section{Comment}

$M$ keratinophilum was reported in 1978 as a new species. ${ }^{1}$ It was isolated from soil in Italy and California, and from the penis of a bull in Germany. The Commonwealth Mycological Institute has identified isolates from the hair of shrews and cats in the United Kingdom and also from an unknown source in Nigeria. The species therefore appears to be widespread in nature, especially where keratinous substrates are present. It is not related to other species that are pathogenic in man.

Although antifungal treatment is indicated in the management of fungal sinusitis, it is unlikely to be effective without surgical intervention, which enables a fresh specimen to be used for isolation and identification of the causal organism. Frontal sinuses should be drained via an enlarged frontal nasal duct and maxillary sinuses through an intranasal antrostomy.

This is the first documented case of fungal infection with $M$ keratinophilum in man. It exhibits many features of aspergillosis of the paranasal sinuses, which affects fit, healthy subjects. Our patient was neither immunosuppressed nor diabetic.

1 Samson RA, Polonelli L. Myriodontium keratinophilum. Genet sp nov. Persoonia

2 Milosev B, Mahgoub ES, Abdel AO, El Hassan AM. Primary aspergilloma of the 3 Miller JW, Johnson A, Lamb D. Allergic aspergillosis of the maxillary sinuses. Thorax $1981 ; 36: 710$.

(Accepted 23 October 1984)

Department of Otolaryngology, Royal Infirmary, Edinburgh EH3 9EN

A G D MARAN, MD, FRCs, head of department

K KWONG, MB, FRCS, registrar

Mycology Unit, Western General Hospital, Edinburgh

L J R MILNE, BSC, PHD, principal mycologist

University Department of Pathology, Medical School, Edinburgh D LAMB, MB, FRCPATH, reader and honorary consultant

Correspondence to: Dr A G D Maran. 